\title{
The outcomes of midline versus medio-lateral episiotomy
} Ratchadawan Sooklim ${ }^{1}$, Jadsada Thinkhamrop*1, Pisake Lumbiganon ${ }^{1}$, Witoon Prasertcharoensuk ${ }^{1}$, Jeerichuda Pattamadilok ${ }^{1}$, Kanok Seekorn ${ }^{1}$, Chompilas Chongsomchai ${ }^{1}$, Prakai Pitak ${ }^{2}$ and Sukanya Chansamak ${ }^{3}$

Address: ${ }^{1}$ Department of Obstetrics and Gynecology, Faculty of Medicine, Khon Kaen University, Khon Kaen, Thailand, ${ }^{2}$ Community Medicine Service Section, Faculty of Medicine, Khon Kaen University, Khon Kaen, Thailand and ${ }^{3}$ Nursing Section, Faculty of Medicine, Khon Kaen University, Khon Kaen, Thailand

Email: Ratchadawan Sooklim - mratchadawan@yahoo.com; Jadsada Thinkhamrop* - jadsada@kku.ac.th;

Pisake Lumbiganon - pisake@kku.ac.th; Witoon Prasertcharoensuk - witoon@kku.ac.th; Jeerichuda Pattamadilok - jeanovich@hotmail.com; Kanok Seekorn - kanok@kku.ac.th; Chompilas Chongsomchai - cchom@kku.ac.th; Prakai Pitak - prakai_pitak@yahoo.com;

Sukanya Chansamak - sukanya_ck@yahoo.co.th

* Corresponding author

Published: 29 October 2007

Reproductive Health 2007, 4:10 doi:10.1186/1742-4755-4-10
Received: 4 August 2006

Accepted: 29 October 2007

This article is available from: http://www.reproductive-health-journal.com/content/4/I/I0

(c) 2007 Sooklim et al; licensee BioMed Central Ltd.

This is an Open Access article distributed under the terms of the Creative Commons Attribution License (http://creativecommons.org/licenses/by/2.0), which permits unrestricted use, distribution, and reproduction in any medium, provided the original work is properly cited.

\begin{abstract}
Background: Episiotomy is the surgical enlargement of the vaginal orifice by an incision of the perineum during the second stage of labor or just before delivery of the baby. During the 1970s, it was common to perform an episiotomy for almost all women having their first delivery, ostensibly for prevention of severe perineum tears and easier subsequent repair. However, there are no data available to indicate if an episiotomy should be midline or medio-lateral. We compared midline versus medio-lateral episiotomy for complication such as extended perineal tears, pain scores, wound infection rates and other complications.

Methods: We conducted a prospective cohort including I,302 women, who gave birth vaginally between April 2005 and February 2006 at Srinagarind Hospital - a tertiary care center in Northeast Thailand. All women included had low risk pregnancies and delivered at term. The outcome measures included deep perineal tears (including perineal tears with anal sphincter and/or rectum tears), other complications, and women's satisfaction at 48 hours and 6-weeks postpartum.

Results: In women with midline episiotomy, deep perineal tears occurred in $14.8 \%$, which is statistically significantly higher compared to $7 \%$ in women who underwent a medio-lateral episiotomy ( $p$-value $<0.05$ ). There was no difference between the groups for other outcomes (such as blood loss, vaginal hematoma, infection, pain, dyspareunia, and women's satisfaction with the method). The risk factors for deep perineal tears were: midline episiotomy, primiparity, maternal height $<145 \mathrm{~cm}$, fetal birth weight $>3,500 \mathrm{~g}$ and forceps extraction.
\end{abstract}

Conclusion: Midline compared to medio-lateral episiotomy resulted in more deep perineal tears. It is more likely deep perineal tears would occur in cases with additional risk factors.

\section{Background}

Episiotomy is the surgical enlargement of the vaginal ori- fice by an incision of the perineum during the second stage of labor or just before delivery and requires repair by 
suturing [1]. During the 1970s, episiotomies were performed on almost all women having their first delivery in order to prevent severe perineal tears and make repair easier. Another commonly cited but unproven benefit of routine episiotomy was the prevention of pelvic relaxation. A number of observational studies and randomized trials showed that routine episiotomy is associated with an increased incidence of anal sphincter and rectal tears [2].

In the Cochrane Database of systematic reviews 1999, restrictive rather than routine use of episiotomy was recommended; however, no indications were given vis-à-vis which type should be used and when, i.e., for assisted vaginal delivery (forceps or vacuum), preterm delivery, breech delivery, predicted macrosomia or a presumed imminent tear. However, we could not identify a clinical trial comparing medio-lateral versus midline episiotomy [3]. At Srinagarind Hospital, our personnel are encouraged to use restrictive episiotomy and to select the type appropriate for each case.

We aimed to evaluate midline versus medio-lateral episiotomy for deep perineal tears, pain scores, wound infection rate and other complications at 48-hours and 6weeks postpartum.

\section{Methods}

This was a prospective cohort study for which we recruited 1,302 pregnant women who gave birth vaginally at Srinagarind Hospital, Khon Kaen University - a tertiary care center in Northeast Thailand - between April 2005 and February 2006. These women had low risk pregnancies according to the following criteria: singleton, cephalic presentation and term pregnancy. All women received episiotomy, either midline or medio-lateral according to attending personnel. Women with spontaneous perineal tears, epidural analgesia and/or any underlying disease (such as diabetes mellitus, chronic renal disease or immune deficiency related diseases) were excluded.

We collected some of the study data from the medical records. The primary outcome was deep perineal tear, defined as a tear with anal sphincter and/or rectum tearing and assessed by the attending physician(s) or nurse(s). The amount of blood loss was estimated by the delivery attendants, based on visual inspection.

Forty-eight hours postpartum the women were asked to complete a pain scoring form after having signed informed consent. We used pain scoring scale of 0 to 10 for 'none' to 'severe' pain regarding the episiotomy wound. Six weeks postpartum, women were interviewed either during the postpartum visit or by telephone for assessment of perineal pain, wound infection, dyspareunia and their satisfaction with the procedure.
We used STATA 9.0 software for Windows (STATA Corp., College Station, TX) for data processing and analysis. Results were reported as means, standard deviations (SD), medians, ranges, relative risks (RR) and $95 \%$ confidence intervals (CI).

This study was approved by the Human Research Ethics Committee of Khon Kaen University.

\section{Results}

Of the 1,302 pregnant women studied, 426 received midline and 876 medio-lateral episiotomy. The baseline characteristics of the two groups are shown in terms of maternal age, weight before delivery, height, parity, gestational age, duration of second stage of labour, fetal birth weight, birth asphyxia, perineal repairing time, amount of blood loss, type of vaginal delivery, type of personnel who performed the delivery and use of antibiotic prophylaxis (Table 1).

Deep perineal tears occurred in 63 of the 426 women with midline episiotomy $(14.79 \%)$, and in 61 of 876 women with medio-lateral episiotomy (6.97\%) (p-value < 0.05). There was no statistically significant difference in blood loss (median $200 \mathrm{ml}$, range $50-100 \mathrm{ml}$ in the midline versus median $200 \mathrm{ml}$, range $50-900 \mathrm{ml}$ in the medio-lateral group) and vaginal hematoma complications after delivery ( $2 / 426$ for midline versus $1 / 876$ for medio-lateral episiotomy).

We were able to assess pain scores and wound infection 48 hours postpartum for 222 of 426 women with midline and 536 of 876 women with medio-lateral episiotomies. There was no difference in pain scores at 48 hours postpartum between the two groups (mean 3, range 0-8 in the midline versus mean 3 , range $0-9$ in the medio-lateral group). One case with wound infection occurred in the medio-lateral episiotomy group.

Among the women studied, we were able to contact with 312 women $(24.0 \%)$ 6-weeks postpartum to assess outcomes. We found no statistically significant difference between the two groups, regarding pain scores (median 0 , range $0-1$ in the midline versus Median 0 , range $0-5$ in the medio-lateral group, p-value 0.13) and satisfaction with the episiotomy procedure $(100 \%$ in the midline versus $99.1 \%$ in the medio-lateral group). There were five women with midline and 19 with medio-lateral episiotomies that had sexual intercourse before six weeks postpartum. There was no difference in dyspareunia between the two groups $(0 / 5$ in the midline versus $3 / 19$ in the mediolateral group) and none of them had any wound infection. 
Table I: Baseline characteristic of the pregnant women studied

\begin{tabular}{|c|c|c|}
\hline Characteristics & Midline episiotomy $(n=426)$ & Medio-lateral episiotomy $(n=876)$ \\
\hline Age (yr, median, min-max) & $28(16-44)$ & $26(12-47)$ \\
\hline Weight before delivery (kg, median, range) & $64(44.3-93.2)$ & $64.8(45.4-96.3)$ \\
\hline Height $(\mathrm{cm}$, mean $\pm \mathrm{SD})$ & $156.7 \pm 5.0$ & 156. \pm 5.2 \\
\hline Gravidity (No., mean \pm SD)) & $1.9 \pm 0.9$ & $1.7 \pm 0.9$ \\
\hline Nulliparous (No., \%) & $206(48.4)$ & $488(55.7)$ \\
\hline Multiparous (No., \%) & $220(51.6)$ & $388(44.3)$ \\
\hline Gestational age (wks, mean $\pm S D)$ & $38.7 \pm 1.3$ & $38.9 \pm 1.2$ \\
\hline Duration of $2^{\text {nd }}$ stage (min, median, min-max) & $13(1-|1|)$ & $14(1-\mid 40)$ \\
\hline Baby birth weight (gm, mean $\pm S D)$ & $3,104.4 \pm 346.5$ & $3,147 \pm 383.9$ \\
\hline $\begin{array}{l}\text { Birth asphyxia. (No., \%) (Apgar score at one } \\
\text { minute } \leq 7 \text { ) }\end{array}$ & $14(3.3)$ & $64(7.3)$ \\
\hline Suture's time $(\mathrm{min}$, mean $\pm \mathrm{SD})$ & $22.75 \pm 11.40$ & $26.15 \pm 12.89$ \\
\hline Estimate blood loss (ml, median, min-max) & $200(50-1,000)$ & $200(50-900)$ \\
\hline \multicolumn{3}{|l|}{ Type of delivery. (No., \%) } \\
\hline I. normal delivery & $379(88.9)$ & $734(84.8)$ \\
\hline 2. forceps extraction & $22(5.7)$ & $49(5.6)$ \\
\hline 3. vacuum extraction & $25(5.9)$ & $84(9.6)$ \\
\hline \multicolumn{3}{|l|}{ Delivery performed by (No., \%) } \\
\hline I. intern & $5(1.2)$ & $57(6.5)$ \\
\hline 2. resident & $155(36.4)$ & $725(82.8)$ \\
\hline 3. staff & $266(62.4)$ & $94(10.7)$ \\
\hline \multicolumn{3}{|l|}{ Suture material. (No., \%) } \\
\hline I. polyglycolic acid & $28(6.6)$ & $57(6.5)$ \\
\hline 2. non polyglycolic acid & $369(86.7)$ & $816(93.2)$ \\
\hline 3. combined & $29(6.8)$ & $3(0.3)$ \\
\hline Antibiotic prophylaxis at LR (No., \%) & $28(6.6)$ & $44(5.1)$ \\
\hline
\end{tabular}

The following risk factors were associated with deep perineal tear: (1) underwent a midline episiotomy (RR 2.12; 95\% CI 1.52 to 2.96 ); (2) primiparity (RR 3.47; 95\% CI 2.27, to 5.31); (3) maternal height $\leq 145 \mathrm{~cm}$ (RR 2.60; $95 \%$ CI 1.19 to 5.67 ); (4) vacuum extraction (RR 1.92; 95\% CI 1.17 to 3.15); (5) forceps extraction (RR 4.04; $95 \%$ CI 2.70 to 6.04 ); and, (6) duration of second stage of labour > 60 minutes (RR 2.30; 95\% CI 1.17 to 4.54 ). We controlled for confounders of the factors affecting deep perineal tears by using a multivariate analysis. The only statistically significant factors were: (1) midline episiotomy (RR $1.94 ; 95 \%$ CI 1.25 to 2.99 ); (2) primiparity (RR 3.56; 95\% CI 2.23 to 5.69); (3) maternal height $\leq 145 \mathrm{~cm}$ (RR 4.22; 95\% CI 2.01 to 8.44); (4) fetal birth weight > $3500 \mathrm{~g}$ (RR 2.22; 95\% CI 1.46 to 3.38); and, (5) forceps extraction (RR 2.82; 95\% CI 1.89 to 4.19) (Table 2).

\section{Discussion}

In this cohort study, 1,302 low risk pregnant women were studied for outcomes related to midline and medio-lateral episiotomies. We found that midline episiotomy resulted in a greater rate of deep perineal tears than medio-lateral episiotomies ( $14.8 \%$ versus $7 \%$ ) but there was no difference between the two groups on other outcomes such as blood loss, hematoma, infection, pain and dyspareunia.
The results of our study are comparable to previous reports regarding deep perineal tears; specifically, Aytan et al. found severe perineal lacerations in 3\% of midline versus $1 \%$ of medio-lateral episiotomies [4] and Angioli et al. reported $6.6 \%$ in midline versus. $4.1 \%$ in medio-lateral episiotomies [5].

We found that the risk factors of deep perineal tears were midline episiotomy, primiparity, maternal height $\leq 145$ $\mathrm{cm}$, baby's birth weight $>3500 \mathrm{~g}$ and forceps extraction. Again, our results are similar to those from previous studies [6-13].

Interestingly, Werner et al. reported that midline episiotomy actually had less hematoma formation and blood loss [12] while we found that vaginal hematoma was the only complication which occurred in the two groups (not statistically different between groups). This is a rare complication and our study might not have had the power to detect the difference.

Coats et al. compared midline and medio-lateral episiotomies in a randomized controlled trial and found no difference in perineal pain immediately and 3 months postpartum [9], comparable to our results. By comparison, Werner et al. found significantly less pain after midline than medio-lateral episiotomies on the third day 
Table 2: Risk factors of deep perineal tear

\begin{tabular}{|c|c|c|}
\hline Risk factors & Univariate analysis $\mathbf{R R}(95 \% \mathrm{Cl})$ & Multivariate analysis RR $(95 \% \mathrm{Cl})$ \\
\hline Midline episiotomy & $2.12(1.52,2.96)^{*}$ & $1.94(1.25,2.99)^{*}$ \\
\hline Maternal age $>35$ yrs., $<20$ yrs. & $0.81(0.49,1.33)$ & $0.94(0.56,1.59)$ \\
\hline Primiparity & $3.47(2.27,5.31)^{*}$ & $3.56(2.23,5.69)^{*}$ \\
\hline Gestational age $>4 \mathrm{I}$ wks. & $0(\alpha, \alpha)$ & $8.39(0, \alpha)$ \\
\hline Maternal height $\leq 145 \mathrm{~cm}$ & $2.60(1.19,5.67)^{*}$ & $4.22(2.01,8.44)^{*}$ \\
\hline Maternal body mass index $>25$ & $0.94(0.65,1.36)$ & $1.01(0.96,1.06)$ \\
\hline Baby birth weight > $3500 \mathrm{gm}$. & $1.5 \mathrm{I}(0.99,2.27)$ & $2.22(1.46,3.38)^{*}$ \\
\hline \multicolumn{3}{|l|}{ Experienced Physician } \\
\hline I. intern & $2.50(0, \alpha)$ & $9.45(0, \alpha)$ \\
\hline 2. resident & $0.48(0.34,0.67)$ & $0.69(0.44,1.08)$ \\
\hline 3. staff & 1 & 1 \\
\hline \multicolumn{3}{|l|}{ Operative vaginal delivery } \\
\hline I. vacuum extraction & $1.92(1.17,3.15)^{*}$ & $1.12(0.62,2.00)$ \\
\hline 2. forceps extraction & $4.04(2.70,6.04)^{*}$ & $2.82(1.89,4.19)^{*}$ \\
\hline 3. normal vg. Delivery & 1 & 1 \\
\hline Duration of second stage $>60 \mathrm{~min}$ & $2.30(1.17,4.54)^{*}$ & $\mathrm{I} .69(0.8 \mathrm{I}, 3.54)$ \\
\hline
\end{tabular}

*statistically significant

postpartum [12]. A limitation to our study might be pain assessment since the proportion of women who gave informed consent and completed the pain scoring form 48 hours postpartum was low and most of our results were drawn from telephone interviews 6-weeks postpartum.

Our study found only one case of wound infection in the medio-lateral episiotomy group at 48 hours which was absent at 6 -weeks postpartum. A previous study by Larsson et al. assessed perineal problems after episiotomy versus spontaneous perineal laceration and found a significantly higher rate of infection in the episiotomy group [14]. But like our results, Harrison et al. found no case of infection for the first four days after delivery or at the 6 week postpartum check-up [15]. By way of corroboration, Owen and Hauth retrospectively reviewed women who had given vaginal birth at the University of Alabama Hospitals and found only ten cases of postpartum perineum infection among 20,713 deliveries, with all of the infectious complications occurring after midline episiotomy [16].

We found that almost all women in both groups were satisfied with their perineum scar. Fewer women in the midline group complained about dyspareunia compared to the medio-lateral group ( 0 versus $15.8 \%$, respectively); however, we cannot absolutely conclude that one is better due to the small number of participants who had sexual intercourse within the 6 -weeks postpartum period. A previous report indicated midline incision was preferable to medio-lateral episiotomy vis-à-vis sexual function, healing, and improved appearance of the perineal scar [17]. However, in our study, we cannot make strong conclusions regarding long-term effects due to the high rate of loss-to-follow-up. Furthermore, in our study, there was no difference on the effect of episiotomy type on blood loss. Theoretically, the line of incision in a midline episiotomy stays within an area where the muscles of the perineum from both sides connect, which should limit blood loss [12]. Additionally, we may have underestimated blood loss by depending on visual inspection instead of using a more objective measuring method. However, we may need randomized controlled trial study to assess the accuracy of the method to estimate blood loss.

Our study may not have been able to account for all possible factors, with a randomized controlled trial being the preferred study design to compare different interventions.

\section{Conclusion}

In this cohort study we would conclude that midline episiotomies resulted in more cases of deep perineal tear compare to medio-lateral episiotomies. Further, deep perineal tears may occur more frequently in cases with additional risk factors. Although a randomized controlled trial (RCT) is the preferred study design to compare different interventions, we were unable to conduct a RCT in our setting. However, the results of our cohort study can pave the way to conduct a well-designed RCT, comparing midline versus medio-lateral episiotomy.

\section{Competing interests}

The author(s) declare that they have no competing interests.

\section{Authors' contributions}

Sooklim R and Thinkhamrop J made substantial contributions to the conception and design, acquisition of data, analysis and interpretation of data; Sooklim R, Pitak P and 
Chansamak S had contribution on data collection; Sooklim R, Thinkhamrop J, Lumbiganon P, Prasertcharoensuk W, Pattamadilok J, Chongsomchai C and Seejorn K were involved in the drafting and revising of the manuscript; Thinkhamrop J and Seejorn $\mathrm{K}$ finalized the version to be published.

\section{Acknowledgements}

We thank the participants without whom the study could not have been done, and which written consent was obtained from the participants or the participants' relatives, the Faculty of Medicine, Khon Kaen University, for financial support, the Clinical Epidemiology Unit for technical support on data processing and analysis, and Mr.Bryan Roderick Hamman for assistance with the English-language presentation of the manuscript.

\section{References}

I. Thacker SB, Banta HD: Benefits and risks of episiotomy: an interpretative review of the English language literature, | 860-I 980. Obstet Gynecol Surv 1983, 38:322-38.

2. Cunningham FG, Leveno KJ, Gilstrap LC III, Hauth JC, Wenstrom KD, Bloom SL: Normal labor and delivery. In Williams Obstetrics 22nd edition. New York: McGraw-Hill companies; 2005:410-40.

3. Carroli G, Belizan J: Episiotomy for vaginal birth. The Cochrane Database of Systematic Reviews 1999, 3:.

4. Aytan H, Tapisiz O, Tuncary G, Avsar FA: Severe perineal laceration in nulliparous woman and episiotomy type. Eur J Obstet Gynecol reprod Biol 2005, I 2 I:46-50.

5. Angioli R, Gomez-Marin O, Cantuaria G, O'Sullivan MJ: Severe perineal laceration during vaginal delivery: the University of Miami experience. Am J Obstet Gynecol 2000, I 82: I083-5.

6. Woolley Rj: Benefits and risks of episiotomy: A review of the English language literature since 1980. Part I. Obstet Gynecol Surv 1995, 50:806-20.

7. Bodner-Adler B, Bodner K, Kaider A, Wagenbichler P, Leodolter S, Husslein $P$, Mayerhofer K: Risk factors for third-degree perineal tears in vaginal delivery, with an analysis of episiotomy types. I Reprod Med 200I, 46(8):752-6.

8. Shiono P, Klebanoff MA, Carey JC: Midline episiotomies: more harm than good? Obstet Gynecol 1990, 75:765-70.

9. Coats PM, Chan KK, Wilkins M, Beard RJ: A comparison between midline and medio-lateral episiotomies. Br J Obstet Gynaecol 1980, 87:408-I2.

10. Helwig JT, Thorp JM, Bowes WA: Does midline episiotomy increase the risk of third- and fourth- degree lacerations in operative vaginal deliveries? Obstet Gynecol I 993, 82(2):276-9.

II. Wood J, Amos L, Rieger N: Third degree anal sphincter tears: risk factors and outcome. Aust N Z J Obstet Gynaecol 1998, 38(4):4|4-7.

12. Werner $\mathrm{CH}$, Schuler W, Meskendahl I: Midline episiotomy versus medio-lateral episiotomy. A randomized prospective study. Int J Gynecol Obstet Proceedings of I 3th World Congress of Gynaecology and Obstetrics (FIGO), Singapore 199I, Book I:33.

13. Jan Zetterstrom, Annika Lopez, Bo Anze: Anal sphincter tear at vaginal delivery: Risk factors and clinical outcome of primary repair. Obstet Gynecol 1999, 94:21-8.

14. Larsson PG, Platz- Christensen J], Bergman B, Wallstersson G: Advantage or disadvantage of episiotomy compared with spontaneous perineal laceration. Gynecol Obstet Invest 1991, 3 I(4):2I3-6.

15. Harrison RF, Brennan M, North PM, Reed JV, Wickham EA: Is routine episiotomy necessary? BMJ 1984, 288: I97|-5.

16. Owen J, Hauth JC: Episiotomy infection and dehiscence. In Infections in pregnancy Edited by: New York: Alan R. Liss. Gilstrap LC III, Faro S; 1990:6I-74.

17. Thacker SB: Midline episiotomy versus mediolateral episiotomy. BMJ 2000, 320:1615-6.
Publish with Bio Med Central and every scientist can read your work free of charge

"BioMed Central will be the most significant development for disseminating the results of biomedical research in our lifetime. "

Sir Paul Nurse, Cancer Research UK

Your research papers will be:

- available free of charge to the entire biomedical community

- peer reviewed and published immediately upon acceptance

- cited in PubMed and archived on PubMed Central

- yours - you keep the copyright

Submit your manuscript here:

http://www.biomedcentral.com/info/publishing_adv.asp
BioMedcentral 